Author version: Published in Care in Translation: Care-ful Research in Medical Settings. Special Issue of East Asian Science, Technology and Society, edited by Catelijne Coopmans and Karen McNamara, Spring 2020, in press.

\title{
Christine Hauskeller
}

Department of Sociology, Philosophy and Anthropology, University of Exeter, UK, email: c.hauskeller@exeter.ac.uk

\section{Care Ethics and Care Contexts: Contributions from Feminist Philosophy ${ }^{1}$}

The substantial and insightful articles in this special issue address different cultural, societal, and regulatory problems of healthcare in contemporary medicine. They include expectations of what good care is, challenges arising from social contexts, and embedded norms affecting practices of care. To these empirical studies I wish to contribute a perspective from feminist philosophy and care ethics that engages with issues in these articles.

Carol Gilligan's (1993) relational care ethics and Susan Sherwin's (1992) approach to a global feminist ethics of healthcare are my entry points for that discussion. Gilligan examines moral judgment empirically and discusses ethical reflections in children, adolescents, and adults, critiquing gender-biased ideals of good moral reasoning. She rejects the view that the most advanced form of moral judgment is characterized by an emphasis on general principles of individual rights and justice. In its place she provides an ethics of "mature care", which is grounded in knowledge of, and respect for, others - as well as for oneself. To this concept of relational ethics, I add the problematizations of healthcare ethics that Susan Sherwin introduces in her analysis of medicine and care as forms of power. She examines medical care practices specifically and problematizes the inherent and external power dynamics that shape them. These power dynamics in healthcare include carers' as well as institutional control over the bodies and minds of patients, but also the status and role of expert knowledge in society, and moreover the global power dynamics between countries and economies surrounding medical technologies and how they affect care practice. The articles in this volume explore such dynamics and illustrate the poignancy of Sherwin's critique as well as the persistent deficit in what, using Gilligan's terminology, I call mature care practices in medicine. Sherwin argues that medicine facilitates the persistence of entrenched inequalities of gender, race, and class within and between countries via ideas of disease and normality. Intersectional feminist and postcolonial critique informs her model of a feminist

\footnotetext{
${ }^{1}$ Acknowledgments: I thank Catelijne Coopmans and Karen McNamara for the invitations to speak at the Framing Technology and Care in Asian Contexts workshop in Singapore in 2017, and to contribute to this special issue. I also thank them and the other reviewers for the critical feedback on an earlier version of this article. Special thanks also go to Jean Harrington, Clara Hick, Tsung-Ling Lee and Sayani Mitra, who commented on an earlier version of this article. Last but not least, I acknowledge the support of the Brocher Foundation in Geneva, where I composed this article as a visiting fellow in 2019 in a very productive, scholarly, and happy work and life environment.
} 
Author version: Published in Care in Translation: Care-ful Research in Medical Settings. Special Issue of East Asian Science, Technology and Society, edited by Catelijne Coopmans and Karen McNamara, Spring 2020, in press.

healthcare ethics, in which she widens Gilligan's mature care approach to reflect on and oppose violent or patronizing practices in medical care within and between societies.

The predominant model of biomedical ethics addresses "good care" mostly as a relationship between physician and patient. The basic framework for contemporary medical ethics that is still widely referred to has been articulated by Beauchamp and Childress (1983). They identify four principles that ought to guide how a medical professional treats a patient, viz. autonomy, beneficence, non-maleficence, and justice. The first three principles are about a relationship between two people. The last, justice, puts the patient in competition with many others for medical care and is commonly understood to be about the fair allocation of scarce resources. This set of principles addresses foremost physicians. It places them at the centre and in charge of managing the patient relation as well as the resources they have at their disposal, including their time and priorities in treatment choices.

Translating such ethical principles into any concrete application inevitably means adapting them to local historical, socio-political, and economic conditions. Social status and power in all their forms - such as gender, class, race and ethnicity, age, and citizenship - come to matter for medical care in practice.

From the feminist perspective I adopt, the articles in this volume present several challenges to the standard model of medical ethics. My aim is to explore how and what these in-depth studies on care contexts and feminist healthcare ethics can contribute to one another. To do that, I draw out aspects from the articles that contribute to critical discourses about medical ethics and underscore the need for mature and fairer healthcare.

\section{$1 \quad$ Problematizing Care}

I begin by noting three main challenges to basic assumptions of classical medical ethics brought to the fore in the articles collected here. The first two show the paradoxical effects of recent technological options on ethical considerations in healthcare, the third challenges the central position of the physician.

The effects of technological mediations in medicine are many. Two of them relate directly to the crucial issue of who the patient is. The first is that the medical profession defines its duty as care for the individual patient. Yet, in Mathangi Krishnamurthy's study on the diagnosis and treatments around a disorder in sex development in India, and in the article by Chia-Ling $\mathrm{Wu}$, Jung-Ok Ha, and Azumi Tsuge on assisted reproductive technologies in Japan, Taiwan and South-Korea, we see that the patient is often not unambiguously one person. Both articles show how the pregnant woman, the foetus, and the family form a complex entity for 
Author version: Published in Care in Translation: Care-ful Research in Medical Settings. Special Issue of East Asian Science, Technology and Society, edited by Catelijne Coopmans and Karen McNamara, Spring 2020, in press.

care in the context of diagnoses of genetic disease or multiplet pregnancy and foetal reduction. In contemporary obstetrics both the woman and the embryo(s) within her have become objects of medical attention. This can create conflicts about who the primary patient is, and these are often shaped by cultural moral values and prescriptive government orders. Karen McNamara's study on the motivations and imaginaries of care that shape medical tourism in South and South East Asia also complicates the question of who the patient is by highlighting how family members are often directly involved in supplying means for, and negotiating the care of, the patient with clinical staff.

Another effect is that most of the new techniques used in diagnosis and treatment provide biophysiological information about organic issues of the patient's body. Technologies have shifted the medical gaze from the patient as a person to features of her body. Jenna Grant's article on medical imaging technologies in the politicized contexts of Cambodia reports doctors expressing ambivalence about the spread of imaging technologies because they see it as leading to reduced skills in other diagnostic and care experience. The problematizations of what is seen as normal in humans are thematic in several articles. Krishnamurthy's as well as Wu and colleagues' article, stress how uses of technologies shape both the ability to accept what may not be quite normal, and the choices made to achieve (more) normality.

A third way in which the articles challenge standard medical ethics concerns the central position of the professional caregiver. Several articles illustrate how family and friends can affect a patient's care context and become part of the treatment setting. In addition, Krishnamurthy's analysis, as well as Chen-I Kuan's study on obstetricians in Taiwan show how physicians are bound by institutional routines in what they can and must do, how and when. Kuan emphasizes how the constrained working conditions in Taiwan force obstetricians to choose between best care provision and a good work-life balance, a choice some avoid by leaving the field for gynaecology.

In my view this signals that medical and healthcare ethics have to take into account societal and institutional practices. The special issue contributions provide insights into how politics and administration shape and constrain medical services through, for instance, funding provisions, allocations of dedicated staff time, and regulations that affect the availability and use of new technologies. They make plain that, while the four principles of medical ethics mark out aspects of a professional ethos and how it might be translated into everyday practice, they fall short of providing a comprehensive approach to examining medical ethics.

The feminist approach I discuss below also highlight that contemporary care contexts are not one-sided physician to patient relations. In Gilligan's mature care ethics, relations are 
Author version: Published in Care in Translation: Care-ful Research in Medical Settings. Special Issue of East Asian Science, Technology and Society, edited by Catelijne Coopmans and Karen McNamara, Spring 2020, in press.

interconnected, part of webs in which individuality is enacted. Sherwin goes much further with her emphasis on how care practices and the conditions that structure them reflect and reaffirm local and even global power hierarchies. Feminist ethics aim for mature care relations and this requires counteracting all forms of oppression.

\section{Gender, Care, and Maturity}

I have become increasingly aware of the crucial role of women's voices in maintaining or transforming a patriarchal world. By becoming actively involved in this process of change, I have found myself and this book at the center of a psychologically and politically volatile debate in which sanity as well as power is at stake. (Gilligan 1993 xii)

In a patriarchal society, not listening to what women have to say is a part of the operations of that power order that keep it intact. In Gilligan's study in moral psychology, In A Different Voice (1993), hermeneutic analysis of interview formats and processes is used to shows that female voices are misunderstood in Lawrence Kohlberg's (1981) theory of moral development. Gilligan rejects the finding that boys progress to advanced moral reasoning at a younger age than girls when asked to solve constructed moral dilemmas on the basis that unchecked gender norms and biases informed the data collection and interpretation. The female study participants tended to consider the relations between the people involved in a dilemma and how they might be affected by an action. Gilligan calls this a "care ethics perspective" and argues that it is not of less value as a moral orientation. Development to moral maturity is not a straight path from rule following via the adolescent questioning of conventional norms to the discovery of individual rights and abstract principles of justice, as Kohlberg had proposed. Mature development for women in a gendered society "proceeds from an initial concern with survival to a focus on goodness and finally to a reflective understanding of care as the most adequate guide to the resolution of conflicts in human relationships" (Gilligan 1993: 105).

Moral maturity is a strongly care-oriented perspective, an ethical attitude towards individual others, a community, and the world - as well as, importantly, oneself. Awareness of and attention to one's own rights and needs and to those of others inform this attitude, which entails seeing oneself as part of a couple, a family, a community - but it does not mean subordinating one's own wishes and rights to what seems best for those larger social units. In experimental data from a study on the topic of abortion with university students, Gilligan finds instances of a self-sacrificing attitude. In follow-up interviews a few years later, some of the former student identify this attitude as having been damaging for themselves. Mature 
Author version: Published in Care in Translation: Care-ful Research in Medical Settings. Special Issue of East Asian Science, Technology and Society, edited by Catelijne Coopmans and Karen McNamara, Spring 2020, in press.

care also means knowing that some relationship problems cannot be solved through more love and care for others, especially if one finds oneself not mutually duly respected as a partner.

\section{Professional Care}

In healthcare one might expect to find professional solutions to avoid conflicts between caring for others and caring for oneself, to avoid carers having to choose between a good personal life and delivering a high standard of care. Kuan's study is a case that shows that this is not always so. The article by Chaoxiong Zhang and Priscilla Song on the methadone maintenance treatment (MMT) programme for heroin addicts in China also discusses care failures with a strong emphasis on political context.

Zhang and Song discuss a 'family' care approach that was tried unsuccessfully at the beginning of the MMT programme. The programme was initiated following the Government's proclamation that love and care ought to dominate this addiction treatment programme. At the same time strict success measures and targets were set that made the MMT programme as a project, as well as the individual carers' careers, dependent on patient behaviour. In this setting mutual dependency characterizes the carer-patient relationship. Some patients understood this dynamic and were found exploiting it. And this, Zhang and Song claimed, made carers critical of providing "excessive care". The relationship dynamics Gilligan considers stipulate that infantilizing adult patients by treating them like dependent children does not support them in acting as competent adults. Not recognizing the realities of either person in any adult relationship contravenes the "recognition conditions" presupposed in a mature care attitude and relationship.

Pregnancy as a unique state of personhood and what this might mean for ethics has long been discussed at the margins of feminist philosophy (Young 1984; Kingma 2019) and is still underexplored. The situation Kuan's interviewees describe is characterized by a care conflict heightened in obstetrics, that is as such not specific to Taiwan. Caesarean section rates ought to be reduced for better maternal and child wellbeing. But in a healthcare context in which the number of midwives is far too low, the task of building a trust relationship with the expecting woman is placed upon the obstetrician. Yet, accompanying a birth process means working for unpredictable periods of time. Personal interests and professional responsibilities compete for obstetricians' (or midwives') time. Moreover, hospitals want to make best use of the time of paid staff, discouraging a long wait for a vaginal delivery. In this conflict of values, mature care according to Gilligan cannot mean either sleeping in the hospital and sacrificing one's personal life nor giving up one's standards of best medical care 
Author version: Published in Care in Translation: Care-ful Research in Medical Settings. Special Issue of East Asian Science, Technology and Society, edited by Catelijne Coopmans and Karen McNamara, Spring 2020, in press.

and conducting caesarean sections without clinical need. Individual carers are warped into a moral double bind and held responsible for their choices. This illustrates that mature care depends on care contexts that prevent such dilemmas, and thus on the institutional organization of care. Indeed, Kuan suggests that changes in attitude to care for women and in care policy are needed.

From a perspective informed by Gilligan's analysis of ethical care relations, patriarchal blind spots regarding what care means and the dilemmas it entails allow such failures and conflicts to arise. Her own case studies confront the underbelly of a patriarchal order in which rights and justice perspectives thrive on a soil of women's caring that is as such disregarded, as are those who do the caring. Gilligan emphasizes that hearing the different voices of women will improve social cohesion and justice as well as our understanding of adult relationships. The rising costs of healthcare are a global political problem and under stretched budgets, the high cost to using new diagnostic or treatment technologies is often weighed against the investment in staff time and training. Mature care demands high quality training and also generous time available from health carers. Moreover, it requires health care regimes in which trusting and professional relationships can be built and practised.

\section{$4 \quad$ Social Contexts of Healthcare}

It appears then that an ethics of healthcare must engage not only with the internal psychology and moral commitments that structure it, but with the situation and the conditions in which it occurs.

A problematic care situation is described from both angles in these and several other articles. For instance, Kuan focuses on the carer's ability to navigate the conflicting wishes, needs, and demands on her time. Zhang and Song focus more on the external conditions which can make it difficult to provide optimal care. They explain that the family approach to care was chosen as a response to state-driven campaigns that mandate care and love (guān'ài) as the right moral attitude towards marginalized groups, among them drug addicts. Kuan also considers the political context and what is promoted in government documents as framing conditions of care.

A different side to this care dilemma, namely patients' perceptions, is articulated by the subjects in McNamara's study. She finds patients suspecting that clinicians act not with an attitude of care and responsibility but in a self-interested manner, putting monetary gain above care. Whilst it would be naïve to deny that this may often be the case, in McNamara's article this suspicion becomes apparent as a facet of the politically-controlled care environment in a country. 
Author version: Published in Care in Translation: Care-ful Research in Medical Settings. Special Issue of East Asian Science, Technology and Society, edited by Catelijne Coopmans and Karen McNamara, Spring 2020, in press.

Ideologies, volatile political priorities, and financial interests shape care. More generally, ideas about good (enough) care are formed and enacted in the multifaceted mundane conditions of institutions. These conditions are constituted by legal texts and court rulings, clinical guidelines, the availability of qualified staff, the local organization of work hours and staffing of a hospital ward, etc. To return to medical ethics, the physician has been shown to be less powerful than is acknowledged in Beauchamp and Childress's four principles.

Furthermore, Kuan, McNamara, Wu et al., and Krishnamurthy report cases where the voice of the female patient is neither listened to nor answered. Medical tourism and consent to interventions that were not wanted show how the responsibility for health outcomes is being shifted from the professional onto the patient, especially in cases where only unsatisfactory treatment options are available. Healthcare ethics must address and confront social and cultural norms and politics that undermine mature healthcare practice.

The principle insight of feminist ethics is that oppression, however it is practiced, is morally wrong. (Sherwin 1992: 54)

When, for example, feminists consider medical research, confidentiality or the new reproductive technologies, they need to ask not only most of the standard moral questions but also the general question of how the issue under consideration relates to the oppression of women and what the implications of a proposed policy would be for the political status of women. (Sherwin 1992: 55)

Biomedical technologies continue to alter how medicine proceeds and foregrounds new ethical problems.

Techniques and technologies that enable diagnosis and treatment distinguish the normal from that which is not, and remodel patients to fit ideas of normality. Krishnamurthy critiques how technologies alter the acceptance of bodies and identities that don't conform to the male or female standard of expectation, as well as the medical interventions that aim to achieve (more) normality. But several articles also present cases where patients are not listened to and not invited to contribute their expertise, with decision-making dominated instead by technologies or normative behaviours that marginalize them.

Sherwin's ethics takes its starting point in practices of recognition, communication, and critical analysis. She configures knowledge about good care as being also held by patients, who are the experts of their own needs, yet often remain unheard. "Once we recognize the need to include oppression as a factor in health, we can no longer maintain the authoritarian 
Author version: Published in Care in Translation: Care-ful Research in Medical Settings. Special Issue of East Asian Science, Technology and Society, edited by Catelijne Coopmans and Karen McNamara, Spring 2020, in press.

medical model, in which physicians are the experts on all matters of health and are authorized to respond to all such threats" (Sherwin 1992: 239).

In many countries the continuation of pregnancy is still not something the pregnant woman can decide upon. At the same time medical professionals ensure that the right kind of children are born, partake in female genital mutilation, or use their skills to adapt patient bodies to cultural norms, risking harm to patients on the basis of questionable criteria for clinical necessity. Medical expertise is a form of power, and it tends to present itself as if untarnished by political power interests. Sherwin believes that recognizing this can help democratize decision-making processes in medicine and foster the development of a feminist mode of care. Medical ethics that are self-limited to pondering the close relations between a few people have no moral position from which to criticize oppressive practices from the outside that charge and disfigure care situations.

Sherwin's feminist ethics of healthcare consider relational ethics in the contexts of both institutional practices of exerting power as well as global differences in status and the care offered to vulnerable or oppressed people.

\section{Politics, Healthcare, and Medical Ethics}

Medicine is one of the institutions through which governments seek to control the social order. Power relations are unequal, dividing those who rule from those who submit to being ruled. Whilst there are various and intersecting criteria determining status and power in complex hierarchical societies, medical or care professions are inevitably operating along the fault lines thus produced. Being in charge of care, they exert some power, being involved in decisions and actions that affect patients' lives.

Sherwin examines diverse intersecting forms of marginalization and oppression, different in different places and for different people, but similar in the hierarchies of sex, race, and class that are effectively reinforced. Her book, No Longer Patient (1992), starts a systematic feminist debate on medical and healthcare ethics and proposes a method for solving the dilemma between value pluralism and respect for different cultures whilst wanting to be able to criticize specific practices as morally wrong. Sherwin discusses medical ethical problems such as abortion and female genital mutilation (FGM) and argues that ethics can criticize certain practices even if they are defended by a population as morally right or customary in their culture. A critical examination of the predominant power structures, and how much influence the groups most hurt by such policies have on actual policy making, allows the assessment of whether the views of the women supporting FGM can be deemed to be freely and autonomously acquired and held. The vicious cycle of oppression consists in 
Author version: Published in Care in Translation: Care-ful Research in Medical Settings. Special Issue of East Asian Science, Technology and Society, edited by Catelijne Coopmans and Karen McNamara, Spring 2020, in press.

being denied a voice that counts, and bodily violated, which diminishes the sense of selfworth and the ability to resist oppressive rules and practices.

In my view feminist medical ethics can counteract these risks by engaging with empirical qualitative research. On that basis a moral philosophical and ethical understanding can criticize harmful or violent practices without remarginalizing women or other groups, and without framing them as holding irrelevant views when they justify such practices as traditional in their culture. Philosophical medical ethics has not generally taken up a mature, critical feminist perspective despite the wealth of material from qualitative social science studies to argue for a richer medical ethics.

The articles in this special issue show that women's voices are often silenced whilst concurrently thereby giving a podium to them. They illustrate how power is politicized and often invisible, and used through and in biomedicine to stabilize unequal social and global hierarchies. Integrating different perspectives on the topic of mature care, we have seen that the investment into healthcare and how it is allocated - for example to excellent staff training or funding the newest diagnostic technologies if both cannot be afforded - affect care conditions and patient experience. Similarly, cultural norms and biases about social status and culture shape care situations, although care professionals are advised to overcome such prejudices in order to provide best clinical practice fairly.

National and cultural rank orders and strategies of presentation affect and maintain particular hierarchies between economies, countries, and cultures. In her quest to understand the motives and experiences that feed medical tourism, McNamara reports a case in which the paradoxes in how the patient and her family understand themselves in those relations are articulated. Trying to do the best one can do for a sick relative may mean taking out loans and bringing them abroad to where treatment is at a higher, Western standard - in this case from Bangladesh to Singapore. When, for example, a patient cannot be cured but still hopes and asks for another MRI scan, the suggestions of the physician to her son to go back to Bangladesh for that scan is devastating. It is perceived by the patient's carer as a personal and cultural insult, demeaning the family's social and economic standing. Hopes and actions are shaped by ideological geopolitical hierarchies, and the intercultural existence of the patient who wants better care appears in its fragility.

The idea that medical care is better in a wealthier country represents an imaginary connection between GDP and healthcare. Such tropes are reinforced in advertisements for medical tourism in poorer countries - by contrast, lower price and reliable delivery/handover are used to sell stem cell therapies or surrogacy in the West. Some 
Author version: Published in Care in Translation: Care-ful Research in Medical Settings. Special Issue of East Asian Science, Technology and Society, edited by Catelijne Coopmans and Karen McNamara, Spring 2020, in press.

governments are complicit in nurturing those ideas and business plans, designing regulations that enable clinical trials or the growth of markets for unproven treatments, reproductive technologies, or beauty surgery.

The articles in this special issue touch upon more ethical issues than I have discussed here. As I have illustrated, they offer new case studies that can inform medical ethics generally and especially a feminist take that focuses on local and geopolitical power regimes and marginalized groups. The specificity of each care situation provides an opening to reflect on its specific wider societal context, as proposed by Sherwin. Feminist care ethics is wellplaced to make norms and attitudes towards gender, class, and politics matter in critiques of medical practice. In-depth studies on care contexts and feminist healthcare ethics can thus inform one another. The biggest challenge feminism raises for classical ethics is that it is demanding. It demands working on oneself and on personal relations as well as on one's attitude to the world, which inevitably includes struggles against immoral practices, cultural values, and political structures. Feminist, postcolonial, and biomedical ethics have a lot of unfinished business.

\section{References}

Beauchamp, Tom L. and James F. Childress (1983). Principles of Biomedical Ethics. Oxford: Oxford University Press.

Gilligan, Carol (1993 [1982]). In A Different Voice: Psychological Theory and Women's Development. Boston: Harvard University Press.

Grant, Jenna (2019) Repair in Translation, EASTS, this issue

Kingma, Elselijn (2019). “Were you a part of your mother?” Mind 128, no. 511: 609-646. Kohlberg, Lawrence (1981). The Philosophy of Moral Development: Moral Stages and the Idea of Justice. New York: Harper and Row.

Krishnamurthy, Mathangi (2019), Navigating the Body Multiple: Biomedicine, genetics and sex/gender in the lives of CAH patients, EASTS this issue

Kuan, Chen-I (2019), Understanding Technology in Birth Care from the Experiences of Taiwanese Obstetricians, EASTS this issue

McNamara, Karen (2019), Rhythms of Care: Medical Travels Beyond the Borders of Bangladesh, EASTS this issue. 
Author version: Published in Care in Translation: Care-ful Research in Medical Settings. Special Issue of East Asian Science, Technology and Society, edited by Catelijne Coopmans and Karen McNamara, Spring 2020, in press.

Susan Sherwin (1992). No Longer Patient: Feminist Ethics and Health Care. Philadelphia: Temple University Press.

Wu, Chia-Ling, Jung-Ok Ha and Azumi Tsuge (2019) Data Reporting as Care Infrastructure: Assembling ART Registries in Japan, Taiwan, and South Korea, EASTS this issue.

Young, Iris Marion (1984). "Pregnant Embodiment: Subjectivity and Alienation." The Journal of Medicine and Philosophy: A Forum for Bioethics and Philosophy of Medicine 9, no. 1: 4562.

Zhang, Chaoxiong, and Priscilla Song (2019) Translating Guān'ài in the People's War on Drugs: Enacting Relations of Care in China's State-Run Methadone Maintenance Treatment, EASTS, this issue.

\section{Author bio:}

Christine Hauskeller is Professor of Philosophy at the University of Exeter and an expert in philosophy of medicine, ethics, feminist philosophy and science and technology studies. She works in teams with social scientists and conducts empirical research into the construction of facts and values, with a focus on normative contradictions and conflicts. Most recent publications include The Matrix of Stem Cell Research. An Approach to Rethinking Science in Society, Hauskeller, Manzeschke, and Pichl (eds.), Routledge, 2019; and a Special Issue of Tecnoscienza: Biobankign Practices: Participation, Identities and Biovalues in the Making, 2018 Vol. 9(2), edited with Lorenzo Beltrame. 